\title{
Net-Zero Energy Buildings and Communities: Potential and the Role of Energy Storage
}

\author{
Marc A. Rosen \\ Faculty of Engineering and Applied Science, University of Ontario Institute of Technology, Oshawa, Canada \\ Email: Marc.Rosen@uoit.ca
}

Received November 2014

\begin{abstract}
Net-zero energy buildings and communities, which are receiving increasing interest, and the role of energy storage in them, are described. A net-zero energy building or community is defined as one that, in an average year, produces as much energy from renewable energy as it consumes. Net-zero energy buildings and communities and the manner in which energy sustainability is facilitated by them are described and examples are given. Also, energy storage is discussed and the role and importance of energy storage as part of net-zero buildings and communities are explained. The NSERC Smart Net-zero Energy Buildings Research Network, a major Canadian research effort in smart net-zero energy buildings and communities, is described.
\end{abstract}

\section{Keywords}

\section{Net-Zero Energy Building, Net-Zero Energy Community, Energy Storage}

\section{Introduction}

Net-zero energy buildings and communities, which in an average year produce as much energy from renewable energy sources as they consume, are becoming increasingly applied and gaining interest. By reducing energy use to net-zero and expanding the use of renewable energy, such buildings and communities facilitate sustainability. Energy storage is a key component of most net-zero energy buildings and communities and a key to their achieving net-zero energy use. This is primarily due to the intermittency of most renewable energy, which necessitates an energy storage capability in order for them to be used to a large extent. In this article, we examine and review the status of net-zero energy buildings and communities and energy storage, as well as needs for better linkages between them. The objective is to improve understanding of these technologies and their needs, and thereby to facilitate increased applications of them and more sustainable use of energy.

\section{Net-Zero Energy Buildings and Communities}

A net-zero energy building is defined as one that, in an average year, produces as much energy (electrical plus thermal) from renewable energy sources as it consumes. A net-zero energy community is similarly defined, but extended from an individual building to a community made up of a group of buildings as well as other components. Various technologies are required in smart net-zero energy buildings and communities (e.g., building-in- 
tegrated solar systems, high performance windows with active control of solar gains, heat pumps, combined heat and power technologies, energy storage technologies ranging from short- to long-term, and smart controls. Much research is ongoing and has been reported in this area [1]-[5].

An example of the growing importance of net-zero energy buildings and communities can be observed through the NSERC Smart Net-zero Energy Buildings Research Network (SNEBRN) (http://www.solarbuildings.ca). SNEBRN is currently the major Canadian research effort in smart net-zero energy buildings and communities, bringing together 29 Canadian researchers from 15 universities, as well as experts from Natural Resources Canada, Hydro-Québec, and other industrial partners. International researchers are also participating in the SNEBRN. The aim is to develop the smart net-zero energy homes, commercial buildings and communities of the future. The vision of SNEBRN is to facilitate widespread adoption in key regions of Canada, by 2030, of optimized netzero energy building design and operation concepts suited to Canadian climatic conditions and construction practices. The various technologies required in smart net-zero energy buildings and communities, mentioned in the previous paragraph, are all undergoing research in SNEBRN.

The Drake Landing Solar Community (DLSC) [6], located in Okotoks, Alberta, Canada and completed in 2006, is an example of a community energy system with several sustainable technologies, including solar energy, thermal energy storage, district heating and heat pumps. DLSC includes 52 low-rise detached homes (138 - 151 $\mathrm{m}^{2}$ in gross floor area), which are located within a 835-home subdivision. DLSC is not a net-zero energy community, as only $90 \%$ of heating and $60 \%$ of hot-water needs are designed to be met using solar energy, but it could be expanded to net-zero energy use. The DLSC project demonstrates the feasibility of replacing substantial residential conventional fuel energy use with solar energy, collected during the summer and utilized for space heating during the following winter, in conjunction with seasonal thermal energy storage.

\section{Energy Storage}

Energy storage is an often hidden-but nonetheless important—energy technology. It can enhance the performance of energy systems, and improve their efficiency, economics, reliability and environmental impact. It is also a key to facilitating the widespread use of many renewable energy resources. Consequently, energy storage, although utilized quietly at present, is likely to be increasingly and more overtly used in the future as pressures from energy costs, security of energy supply and environmental damage expand.

This growth in interest in energy storage was recently emphasized in Ontario, via that province's recent LongTerm Energy Plan, which calls for the procurement of 50 MW of energy storage capacity by the end of 2014. Consequently, an energy storage procurement framework was jointly submitted by the Independent Electricity System Operator (IESO) and Ontario Power Authority (OPA), and supported by the Minister of Energy in the province. The procurement framework allows for a diverse portfolio of energy storage technologies, so as to foster improved understanding of and experience with 1) the services energy storages can provide, 2) the benefits they bring to operations and 3) how storage can best be integrated into electricity markets. In Phase I of the procurement framework, released March 12, 2014, the IESO issued a request for proposals for up to $35 \mathrm{MW}$ of grid energy storage capacity from various storage technologies that can provide ancillary and other grid services (e.g., energy time-shifting, transmission congestion relief).

Some of the benefits of energy storage, which often are quite significant, follow:

- When energy demand varies significantly temporally, energy storage allows peak demands to be reduced or shifted to periods of lower demand, often with significant economic advantages.

- Energy storage is especially helpful for bridging periods between energy supply and energy demand, and reducing the mismatches between periods of energy supply and demand.

- The performance of energy systems that incorporate intermittent energy sources is made much more effective through the use of energy storage.

- Energy storage facilitates the utilization of many renewable energy sources which, due to their intermittent nature, are often not available when energy services are required. Wind and solar energy technologies, for instance, often benefit from storages that allow the energy products to be held until needed, if they are not required when the wind is blowing or the sun is shining.

- Increased operational performance flexibility can be provided through the use of energy storage.

- Energy storage can reduce use of fossil fuels and their associated environmental impacts. 
A broad range of types of energy storage technologies and systems exists (see Figure 1). These can be separated into as chemical, electrical, thermal, thermochemical, mechanical and other classifications. Specific types of energy storage include battery storage, hydrogen energy storage, flywheel energy storage, compressed-gas energy storage, pumped storage, magnetic storage, capacitor storage, chemical storage, thermal energy storage (both sensible and latent), thermochemical energy storage, organic and biological energy storage, and others. Although much energy storage is mature and commercially available, new storage technologies are being actively investigated and improvements to existing ones continually sought. Some technologies are both commercial at present but also undergoing extensive research, e.g., thermal energy storage [6].

Energy storage can be utilized in a wide range of applications (see Figure 2). The main types of applications include utility and other electrical power systems, conventional and renewable power generation, renewable energy sources, transportation, heat pumps, building heating and cooling and district energy systems. The ability of energy storage to facilitate the efficient, effective and economic operation of renewable energy systems is particularly noteworthy, e.g., energy storage to improve solar power plants, as is the ability of energy storage to facilitate the design and operation of net-zero energy buildings and communities.

A recent book by the author describes energy storage from several perspectives, providing a broad understanding and appreciation of the technology and its importance and benefits [7]. Included in the book are descriptions of energy storage technology and systems, updates on the status of technological development of energy storage technology, and recent advances in energy storage technologies, systems and applications. The book is organized into several parts, mainly based on category of energy storage, which highlight the diversity of storage types and applications:

- General energy storage concepts, technologies and methods, including an overview of the technology and methods for evaluating efficiencies of energy storage systems.

- Hydrogen energy storage, including descriptions of hydrogen storage on such materials as magnesium hydride, porous materials and hydrogen-based compounds.

- Electrical energy storage, including emerging energy storage technologies in utility power systems, water storage for storing electricity to facilitate renewable energy use, double layer capacitors for electrical storage, and energy storage technologies for future power systems.

- Thermal energy storage, including descriptions of thermal storage media for solar thermal power plants, the performance of phase change materials and geothermal storage, and applications of thermal energy storage in building heating and cooling and district energy.

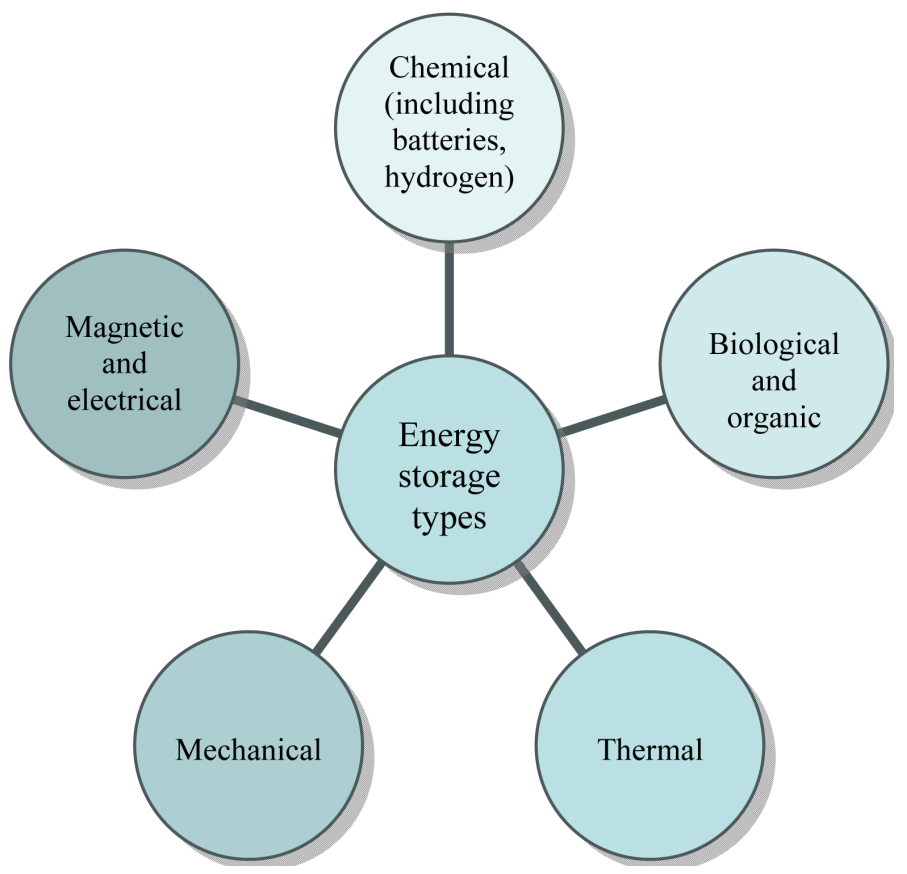

Figure 1. Energy storage types classified by type of stored energy. 


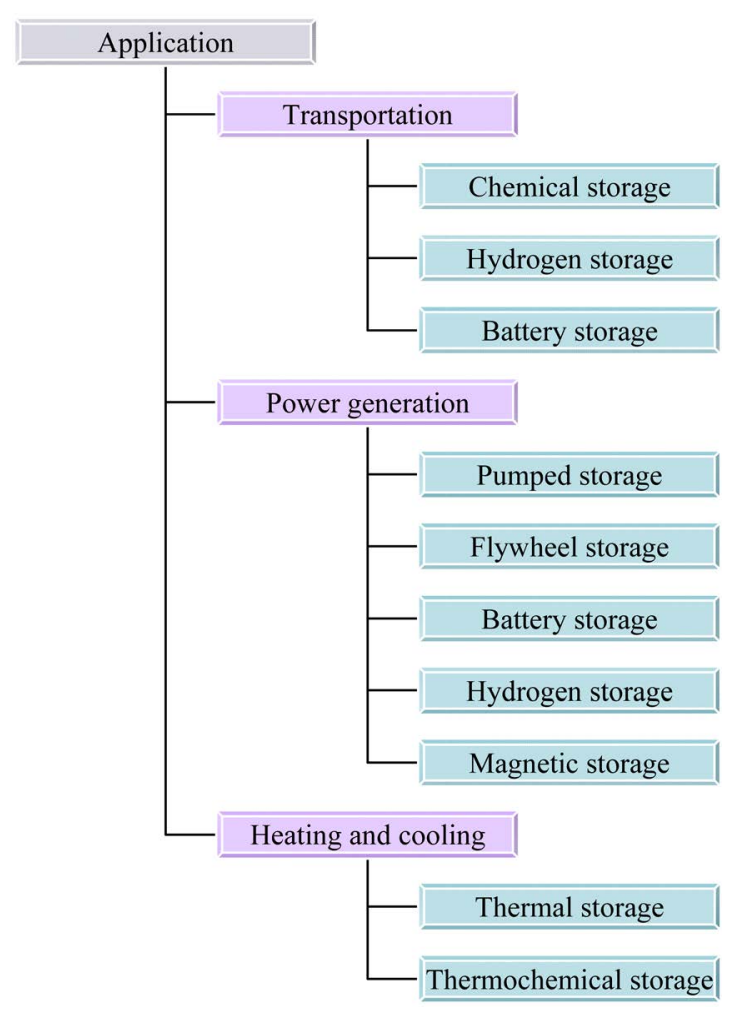

Figure 2. Selected energy storage application, based on area of utilization.

- Thermochemical energy storage, including a description of the technology and applications.

The benefits of and need for energy storage make it of interest wherever energy is used throughout the world. Global interest in energy storage technologies and applications is evident from the chapters in the above mentioned book, which originate from several countries: Canada, United States, Argentina, France, Italy, Denmark, Croatia, Iran, Japan and Thailand.

\section{Needs for Linking Energy Storage with Net-Zero Energy Buildings and Communities}

Research is required on linking energy storage with net-zero energy buildings and communities. Although smart net-zero energy buildings and communities require various technologies (e.g., solar energy, high performance windows, heat pumps, combined heat and power, smart controls), they hinge on the use of energy storage technologies, ranging from short- to long-term. In fact, one of the five main themes of the NSERC Smart Net-zero Energy Buildings Research Network is mid- to long-term thermal storage for buildings and communities.

Numerous needs exist regarding the linkages between energy storage and net-zero energy buildings and communities, so as to facilitate more advantageous and widespread applications:

- The appropriate scale and number of energy storages in a net-zero energy community need to be better assessed. Some efforts have focused on single storages scaled to a size appropriate for a given community, while others have focused on multiple smaller storages appropriately located throughout the community. Although smaller storages tend to have higher losses, other efficiency advantages of multiple storages in community settings can make them advantageous.

- The appropriate time duration capacities of energy storages in a community need to be determined. Longterm storage (based on seasonal or annual storage cycles) is preferred for some community energy systems, while short-term (diurnal) and mid-term (weekly) thermal storages are appropriate for others. Sometimes, a combination of short-, medium- and long-term storage is required to yield the most benefits from community energy systems. For example, the Drake Landing Solar Community described earlier uses a combination of 
seasonal ground-based thermal storage with short-term liquid storage tanks.

- The appropriate type of energy storage(s) in a community energy system need to be better analyzed and identified. For instance, thermal energy storage is often employed, based on sensible, latent, thermochemical and combined modes.

- Developments are needed in energy storage technology and systems for net-zero buildings and communities, in terms of factors such as efficiency, reliability, economics, environmental impact and others, so as to achieve optimal performance.

\section{Conclusion}

Net-zero energy buildings and communities are being applied and interest in them is growing. Energy storage plays a key role in net-zero buildings and communities. Net-zero energy buildings and communities are being investigated actively in many countries, e.g., the NSERC Smart Net-zero Energy Buildings Research Network is expanding knowledge in this field and bringing together researchers and practitioners. Net-zero energy buildings and communities and energy storage technologies are becoming more effective and advantageous, making applications likely to expand and permitting better and more sustainable energy systems.

\section{Acknowledgements}

Support was provided by the Natural Sciences and Engineering Research Council of Canada.

\section{References}

[1] Bucking, S., Athienitis, A. and Zmeureanu, R. (2013) An Information Driven Hybrid Evolutionary Algorithm for Optimal Design of a Net Zero Energy House. Solar Energy, 96, 128-139. http://dx.doi.org/10.1016/j.solener.2013.07.011

[2] Berggren, B., Hall, M. and Wall, M. (2013) LCE Analysis of Buildings: Taking the Step towards Net Zero Energy Buildings. Energy and Buildings, 62, 381-391. http://dx.doi.org/10.1016/j.enbuild.2013.02.063

[3] Gaiser, K. and Stroeve, P. (2014) The Impact of Scheduling Appliances and Rate Structure on Bill Savings for NetZero Energy Communities: Application to West Village. Applied Energy, 113, 1586-1595. http://dx.doi.org/10.1016/j.apenergy.2013.08.075

[4] Cellura, M., Guarino, F., Longo, S. and Mistretta, M. (2014) Energy Life-Cycle Approach in Net Zero Energy Buildings Balance: Operation and Embodied Energy of an Italian Case Study. Energy and Buildings, 72, 371-381. http://dx.doi.org/10.1016/j.enbuild.2013.12.046

[5] Mohamed, A., Hasan, A. and Sirén, K. (2014) Fulfillment of Net-Zero Energy Building (NZEB) with Four Metrics in a Single Family House with Different Heating Alternatives. Applied Energy, 114, 385-399. http://dx.doi.org/10.1016/j.apenergy.2013.09.065

[6] Dincer, I. and Rosen, M.A. (2011) Thermal Energy Storage. 2nd Edition, Wiley, London.

[7] Rosen, M.A. (2012) Energy Storage. Nova Science Publishers, Hauppauge. 